\title{
Effect of Coaching in Diabetes Program in Glycemic Control in Steelworkers
}

\section{Efecto del programa de coaching en diabetes en el control glucémico en trabajadores del acero}

\author{
Dalia GutiérRez-GonZÁlez¹, Rosalinda GonZÁlez-Facio², Oscar M. Cantú-Santos², \\ AND MA. ELENA ROMERO-IBARgUENGOITIA ${ }^{1 *}$
}

${ }^{1}$ Research Department; ${ }^{2}$ Internal Medicine. Hospital Clínica Nova, San Nicolás de los Garza, Nuevo León, Monterrey, Mexico

\section{ABSTRACT}

\begin{abstract}
Background: CoachingenDiabetes (CoeD) is a multidisciplinary program created for steelworkers and their families with type 2 diabetes mellitus (T2DM) and $\mathrm{HbA} 1 \mathrm{c} \geq 9 \%$ to improve blood glucose levels. Objective: To assess the program's impact on glycemic control after 2 years. Methods: This was a retrospective and longitudinal study of uncontrolled T2DM at Hospital Clínica Nova in Mexico. The effect of CoeD on glycemic control was evaluated from May 2017 to 2019. Results: CoeD included 153 (115 [75.2\%] males) patients, with a mean (SD) age of 62.9 (11.2) years. The duration of T2DM was 9.7 (6.6) years. A decrease in $\mathrm{HbA} 1 \mathrm{c}$ of $1.5 \%$ (mean [SD] 9.8\% [1.5]-8.3\% [1.6], $\mathrm{p} \leq 0.05)$ and in fasting glucose of $41.8 \mathrm{mg} / \mathrm{dl}$ (mean [SD] $180 \mathrm{mg} / \mathrm{dl}$ [67]-138.2 mg/dl [55], $\mathrm{p} \leq 0.05$ ) was observed through 2-year follow-up. Emergency room visits or hospitalization rates and the incidence of most comorbidities related to diabetes remained stable over time. Conclusions: CoeD successfully improved and sustained glycemic control in male steelworkers and their families with $\mathrm{HbA} 1 \mathrm{c} \geq 9 \%$ over a 2-year follow-up.
\end{abstract}

Keywords: Type 2 diabetes mellitus. Diabetes education. Glycated hemoglobin A. Chronic complications. Occupational health.

\section{RESUMEN}

\begin{abstract}
Antecedentes: Coaching en diabetes (CoeD) es un programa multidisciplinario creado para los trabajadores del acero y sus familias con diabetes tipo 2 (DM2) y hemoglobina glucosilada $(\mathrm{HbA} 1 \mathrm{c}) \geq 9 \%$, para mejorar los niveles de glucosa en sangre. Objetivo: Evaluar el impacto del programa en el control glucémico después de dos años. Métodos: Estudio retrospectivo y longitudinal de DM2 no controlada en el Hospital Clínica Nova. El efecto del CoeD sobre el control glucémico se evaluó desde mayo de 2017 hasta 2019. Resultados: El CoeD incluyó 153 (115 [75.2\%] varones) pacientes, con una edad media de 62.9 (desviación estándar [DE]: 11.2) años. La duración de la DM2 fue de 9.7 (DE: 6.6) años. Una disminución en la HbA1c del 1.5\% [9.8\% (DE: 1.5 ) a $8.3 \%$ (DE: 1.6$) ; p<0.05$ ) y en la glucosa en ayunas de $41.8 \mathrm{mg} / \mathrm{dl}$ (180 mg/dl [67] a $138.2 \mathrm{mg} / \mathrm{dl}$ [55]; $\mathrm{p}<0.05)$ durante un seguimiento de dos años. La tasa de visitas a urgencias o de hospitalización y la incidencia de la mayoría de las comorbilidades relacionadas con la diabetes se mantuvo a lo largo del tiempo. Conclusiones: El CoeD logró mejorar y mantener el control glucémico en trabajadores siderúrgicos y sus familias, con $\mathrm{HbA} 1 \mathrm{c} \geq 9 \%$ durante un seguimiento de dos años.
\end{abstract}

Palabras clave: Diabetes mellitus tipo 2. Educación en diabetes. Hemoglobina A glucosilada. Complicaciones crónicas. Salud ocupacional.

\section{Correspondence:}

*Ma. Elena Romero-lbarguengoitia

E-mail: mromeroi@novaservicios.com.mx
Date of reception: 07-01-2021

Date of acceptance: 09-04-2021

DOI: 10.24875/RME.21000001
Available online: $22-02-2022$

Rev Mex Endocrinol Metab Nutr. 2022;9:13-9

2462-4144 / @ 2021 Sociedad Mexicana de Nutrición y Endocrinología, AC. Published by Permanyer. This is an open access article under the terms of the CC BY-NC-ND license (http://creativecommons.org/licenses/by-nc-nd/4.0/). 


\section{INTRODUCTION}

According to the International Diabetes Federation, diabetes is a global health problem, with a prevalence of 463 million people in 2019'1 In Mexico, according to the National Health Survey (ENSANUT 2018), $10.3 \%$ of 8.6 million interviewed adults (11.4\% of women and $8.4 \%$ of men) had diabetes ${ }^{2}$.

Lack of control in chronic degenerative diseases such as diabetes leads to greater risks for workers and the labor environment. Likewise, work absenteeism increases ${ }^{3}$. According to different studies, strict glycemic control has been shown to decrease the mortality and complications of diabetes ${ }^{4,5}$.

Besides strict control with drugs, multidisciplinary management has improved diabetes outcomes, especially in groups with uncontrolled glycemia resulting from poor treatment adherence ${ }^{6,7}$. This management type may include individualized or group sessions with an attending physician, a diabetes educator, a physical trainer, a nutritionist, or a psychologist, among other specialists ${ }^{8}$. However, these multidisciplinary treatment strategies have a variable response depending on the program's cultural appropriation and the type of patient group ${ }^{9-11}$; they have not been evaluated in steelworkers with difficulties controlling their disease.

Hospital Clínica Nova (HCN) is a health system that cares for steelworkers and their families who work at the Ternium Company in Monterrey, Mexico. Medical services are provided to approximately 45,000 patients. The prevalence of type 2 diabetes mellitus (T2DM) in the past 3 years has been $10.17 \%$. Of these patients, 9.73\% have reported an $\mathrm{HbA1c}$ above $9 \%$ (data not published). Therefore, the clinic created a multidisciplinary intervention program named Coaching en Diabetes (CoeD) to improve steelworkers' health with poor adherence to medical treatment and an $\mathrm{HbA} 1 \mathrm{c} \geq 9 \%$. It began in 2017 as an institutional intervention policy, and it remains active to date. However, how the program has influenced the glycemic control of the involved patients remains unknown, so we designed this study to analyze the effect at 2 years of the CoeD program on glycemic control in steelworkers with T2DM and their families at $\mathrm{HCN}$.

\section{MATERIALS AND METHODS}

The study was retrospective and longitudinal and followed the STROBE guidelines ${ }^{11}$. It included patients with T2DM managed in the CoeD program in the HCN between May 2017 and May 2019. It was approved by the local IRB (Ref.:29112019-a-MI-CN-Cl) and conducted per the Code of Ethics of the World Medical Association (Declaration of Helsinki) for experiments involving humans. Due to the study's retrospective nature, the consent form was waived. However, the CoeD program did require participants to sign an informed consent form to participate.

The CoeD program consisted of selecting steelworkers or their families with poor adherence to medical treatment. This was defined according to the results in the monthly $\mathrm{HbA} 1 \mathrm{c}$ laboratory report provided to the Internal Medicine department, low attendance to the clinic $(<1$ time in a year), and poor attachment to medical, nutritional, and physical activity advice.

The inclusion criteria were individuals with a previous diagnosis of T2DM, according to ADA criteria, between the ages of 18 and 90 years, both genders, and $\mathrm{HbA} 1 \mathrm{c} \geq 9 \%$, and an available electronic medical record. Patients were excluded if they had other types of diabetes, had lost their medical service, and were pregnant women.

Selected patients were invited to participate in the CoeD program through phone calls by social workers or occupational medicine department personnel. The program consisted of a single group medical visit and multiple individual visits with medical providers. The group medical sessions, each lasting $90 \mathrm{~min}$, had a weekly schedule and were directed by a multidisciplinary team. This group was integrated by an internist (coordinator), a nutritionist, a diabetes educator, and social work staff. In cases where the patient was an active steelworker, an occupational medicine physician was included in the group. Every session included a maximum of three patients. Each patient could bring a companion if they wished, but it was not obligatory.

The session content was standardized and was the same for each patient. It began with a brief 
introduction, and patients were asked to sign the informed consent form to participate in the program. Then, the coordinator gave a lecture concerning the importance of diabetes control using a culture-centered approach, emphasizing awareness of the disease's risks and the importance of a good quality of life for the patients and their families' quests to empower each individual. Each patient was guided to identify what personal factors hindered good patient adherence to treatment; if his conjectures were accepted, the patient shared his experience with the rest of the group.

In the past $20 \mathrm{~min}$, the nutritionist presented recommendations on how to follow a healthy diet. At the end of the session, the patients signed a document of commitments and goals to achieve a glycemic target, and the social work staff scheduled appointments with internal medicine, nutrition, diabetes education, ophthalmology, and other specialties if needed. Follow-up was every 3-6 months, depending on the specialist's requirements.

We analyzed the following variables retrospectively: age, gender, duration of diabetes, marital status, blood pressure $(\mathrm{mmHg})$, and body mass index (BMI). We also described the progression of comorbidities (presence/absence reported in the medical chart), such as retinopathy, peripheral neurological symptoms, renal disease, heart failure, stroke, amputations, heart attack, and angina.

Finally, we described changes in the medical prescription of oral drugs and insulin, death, need for emergency room (ER) visits, and hospitalizations. The analyzed biochemical variables were $\mathrm{HbA} 1 \mathrm{c}$ (percentage) (equipment D-10, BioRad, U.S.A.), and fasting glucose $(\mathrm{mg} / \mathrm{dl}$ ) (equipment Architect c4000 Abbot U.S.A). All variables were recorded at $0,6,12$, 18 , and 24 months after attending the CoeD session.

The study is an interim analysis of the program's performance in its first 2 years. Two researchers reviewed the quality control of the database. Normality assumption was evaluated with the Shapiro-Wilk test and frequency histograms.

Descriptive statistics, such as mean, the standard deviation for quantitative variables, frequencies, and percentages for categorical variables, were computed. Repeated measures ANOVA (to control multiple testing) and Cochran's $\mathrm{Q}$ analysis were used to evaluate the program's effect on continuous and categorical quantitative variables over time. A change in $\mathrm{HbA} 1 \mathrm{c}$ of at least $0.5 \%$ during the intervention overtime was considered successful.

Missing data were handled with the analysis of complete cases and multiple imputations $(<20 \%$ of missing values). The sample size was calculated according to the repeated measures ANOVA formula. With an effect size of 0.5 , five measurements, an alpha of 0.05 , and a power of $80 \%$, the sample size required for this study was 35 patients. Since only three patients are included per group session, individuals have different initiation dates and follow-up periods. We expect different sample sizes when analyzing each follow-up duration.

The statistical programs used were the G Power program, version 3.1.9.4, and SPSS, version 25. The analysis was two tailed. $p \leq 0.05$ was considered statistically significant.

\section{RESULTS}

The total of 153 patients that were accepted to participate in the CoeD program throughout the study period was analyzed. One hundred and fifteen patients $(75.2 \%)$ were male steelworkers, 38 (24.8\%) were female, and the metal industry workers' relatives. The mean (SD) age was 62.9 (11.2) years, and 148 (97\%) patients were married. The duration of diabetes was 9.7 (6.6) years. Furthermore, 68 (44.4\%) had arterial hypertension. The mean (SD) BMI was 30.8 (4.9).

From the initial sample, $149(97.4 \%)$ have completed the 6-month follow-up, 102 (66.7\%) at 12 months, 53 (34.6\%) at 18 months, and $36(23.5 \%)$ at 24 months.

Compared with the baseline value, $\mathrm{HbA} 1 \mathrm{c}$ decreased in the first 6 months by $1.5 \%(p=0.032)$ and was maintained throughout the 24-month follow-up. Fasting glucose decreased $34.2 \mathrm{mg} / \mathrm{dl}$ the first 6 months and a total of $41.8 \mathrm{mg} / \mathrm{dl}$ through 24 months $(p=0.021)$ (Fig. 1 and Table 1). Blood pressure and BMI remained unchanged $(p>0.05)$. Their blood 
Table 1. Clinical and biochemical measurements

\begin{tabular}{|c|c|c|c|c|c|c|}
\hline Characteristics/time & Baseline & 6 months & 12 months & 18 months & 24 months & p-value* \\
\hline $\begin{array}{l}\operatorname{HbA1c}(\%) \\
\mathrm{n}(\%)\end{array}$ & $\begin{array}{l}9.8(1.5)^{\mathrm{a}} \\
153(100)\end{array}$ & $\begin{array}{l}8.3(1.7)^{\mathrm{b}} \\
117(78.5) \\
\end{array}$ & $\begin{array}{l}8.4(1.7)^{\mathrm{b}} \\
85(83.3)\end{array}$ & $\begin{array}{l}8.8(2.3)^{\mathrm{b}} \\
46(86.8)\end{array}$ & $\begin{array}{l}8.3(1.6)^{b} \\
31(86.1) \\
\end{array}$ & 0.032 \\
\hline $\begin{array}{l}\text { Fasting glucose }(\mathrm{mg} / \mathrm{dl}) \\
\mathrm{n}(\%)\end{array}$ & $\begin{array}{l}180(67)^{\mathrm{a}} \\
153(100)\end{array}$ & $\begin{array}{c}145.8(62.8)^{b} \\
124(83.2)\end{array}$ & $\begin{array}{c}142.4(50.8)^{b} \\
85(83.3)\end{array}$ & $\begin{array}{c}142(55.2)^{b} \\
46(86.8)\end{array}$ & $\begin{array}{l}138.2(55)^{\mathrm{b}} \\
32(88.9)\end{array}$ & 0.021 \\
\hline $\begin{array}{l}\mathrm{BMI}\left(\mathrm{kg} / \mathrm{m}^{2}\right) \\
\mathrm{n}(\%)\end{array}$ & $\begin{array}{l}30.8(4.9) \\
147(96.1) \\
\end{array}$ & $\begin{array}{l}30.8(5.1) \\
116(77.8)\end{array}$ & $\begin{array}{l}31.1(5.1) \\
86(84.3)\end{array}$ & $\begin{array}{l}30.6(4.1) \\
41(77.4) \\
\end{array}$ & $\begin{array}{l}29.3(4.6) \\
34(94.4) \\
\end{array}$ & $>0.05$ \\
\hline $\begin{array}{l}\text { Systolic blood pressure } \\
(\mathrm{mm} \mathrm{Hg}) \\
\mathrm{n}(\%)\end{array}$ & $\begin{array}{l}124(13.5) \\
146(95.4)\end{array}$ & $\begin{array}{l}125(13) \\
128(85.9)\end{array}$ & $93(91.2)$ & $50(94.3)$ & $\begin{array}{l}124(11) \\
35(97.2)\end{array}$ & $>0.05$ \\
\hline $\begin{array}{l}\text { Diastolic blood pressure } \\
(\mathrm{mm} \mathrm{Hg}) \\
\mathrm{n}(\%)\end{array}$ & $\begin{array}{c}76(8) \\
146(95.4)\end{array}$ & $\begin{array}{c}76(9) \\
128(85.9)\end{array}$ & $\begin{array}{c}78(8) \\
93(91.2)\end{array}$ & $\begin{array}{c}74(6) \\
50(94.3)\end{array}$ & $\begin{array}{c}73(8) \\
35(97.2)\end{array}$ & $>0.05$ \\
\hline
\end{tabular}

Data are presented mean (SD) and frequencies (percentage). ANOVA of repeated measures was performed for comparisons over time. ${ }^{*} \mathrm{p}$-value for multiple comparison ANOVA; a-bpost hoc - comparison between groups: the group's different letters mean the statistical difference among them. SD: Standard deviation, BMI: Body mass index, HbA1c: Glycosylated hemoglobin

pressure was in the target range throughout the study. In Table 1, clinical and biochemical measurements are described. There was an increase in the prescription of alogliptin $(p<0.001)$, alogliptin/metformin ( $p<0.001)$, dapagliflozin $(p=0.027)$, and glargine U-100 ( $p=0.017)$. Prescription of sitagliptin/ metformin decreased $(p<0.001)$ due to its scarcity in the clinic. Frequencies and changes in medications are presented in Table 2.

Patients increased attendance to internal medicine department from less than once a year to at least every 6 months through 2 years in $99 \%$ of the patients. The attendance to diabetes education, nutrition, physical activity, and ophthalmology department was $54-84 \%$ through the program period.

Peripheral neurological symptoms increased throughout follow-up ( $<<0.001)$, while other comorbidities remained stable (Table 3 ). In the previous 3 months before starting the program, the ER visits were present in 40 patients $(26.1 \%, \mathrm{n}=153$; 0-3 events per patient). The main reasons were related to hyperglycemia in $11 \%$, work accidents in $25 \%$, and other $62 \%$. After 2-year follow-up, it changed to 11 (30.6\%, n = 36, 0-3 events per patient). The main reasons were angina in $9 \%$ angina, work accidents $18 \%$, and other reasons $73 \%$. Before the program, five patients were hospitalized (3.3\%, $\mathrm{n}=153,0-2$ events per patient), $20 \%$ in relation to

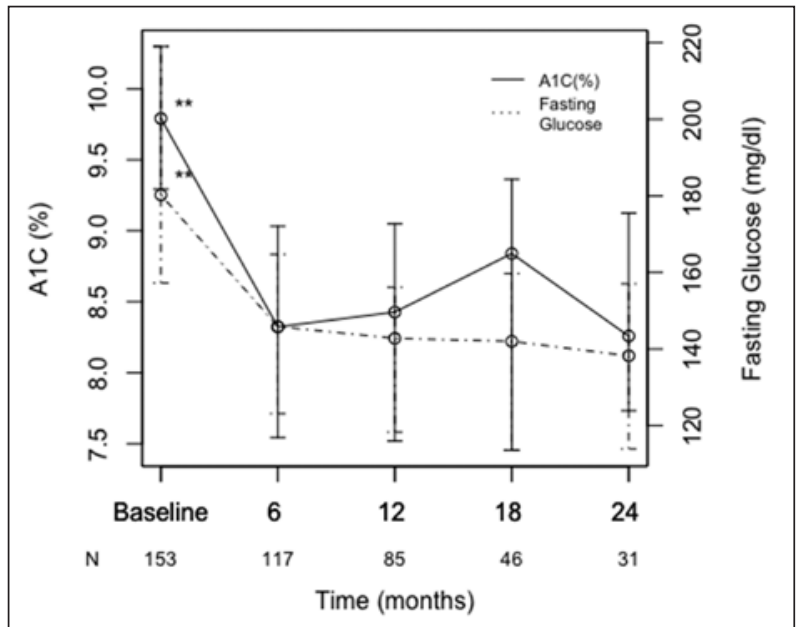

Figure 1. Change in $\mathrm{HbA} 1 \mathrm{c}$ and fasting glucose. Change of $\mathrm{HbA} 1 \mathrm{c}$ (\%) and fasting glucose $(\mathrm{mg} / \mathrm{dl})$ through time. ${ }^{* *} \mathrm{p}<0.05$.

hyperglycemia, $20 \%$ in relation to work accidents, and $60 \%$ other reasons, and during 2-year follow-up, $3(8.3 \%, n=36,0-2$ events per patient) and 2 of them in relation to cardiovascular disease $(p>0.05)$.

Twenty-six (17\%) patients abandoned the program. Their main reasons were 11 (42.3\%) without a specific cause, 9 (34.6\%) partially abandoned the program for at least 6 months but later returned, 2 (7.6\%) lost their medical service, 2 (7.6\%) patients became pregnant during follow-up, and 2 (7.6\%) subjects died, one at the age of 54 and the other at the age of 64 years, due to cardiovascular disease. 
Table 2. Oral drugs and insulin

\begin{tabular}{|c|c|c|c|c|c|c|}
\hline Drugs/time & $\begin{array}{l}\text { Baseline, } \\
\mathrm{n}=153\end{array}$ & $\begin{array}{c}6 \text { months, } \\
\mathrm{n}=140\end{array}$ & $\begin{array}{c}12 \text { months, } \\
\mathrm{n}=99\end{array}$ & $\begin{array}{c}18 \text { months, } \\
n=52\end{array}$ & $\begin{array}{l}24 \text { months, } \\
n=36\end{array}$ & p-value* \\
\hline Metformin & $131(85.6)$ & $118(79.2)$ & $73(71.6)$ & $35(66)$ & $24(66.7)$ & $>0.05$ \\
\hline Acarbose & $10(6.5)$ & $11(7.4)$ & $8(7.8)$ & $7(13.2)$ & $4(11.1)$ & $>0.05$ \\
\hline Sitagliptin/metformin & $62(40.5)$ & $44(29.5)$ & $27(26.5)$ & $16(30.2)$ & $3(8.3)$ & $<0.001$ \\
\hline Pioglitazone & $14(9.2)$ & $12(8.2)$ & $8(7.8)$ & $4(7.5)$ & $2(5.6)$ & $>0.05$ \\
\hline Glimepiride & $9(5.9)$ & $8(5.4)$ & $4(3.9)$ & $1(1.9)$ & $2(5.6)$ & $>0.05$ \\
\hline Glibenclamide & $2(1.3)$ & $1(0.7)$ & $3(2.9)$ & $1(1.9)$ & $0(0)$ & $>0.05$ \\
\hline Alogliptin & $24(15.7)$ & $56(37.6)$ & $31(30.4)$ & $19(35.8)$ & $16(44.4)$ & $<0.001$ \\
\hline Alogliptin/metformin & $19(12.4)$ & $41(27.5)$ & $34(33.3)$ & $20(37.7)$ & $21(58.3)$ & $<0.001$ \\
\hline Dapagliflozin/metformin & $11(7.2)$ & $13(8.7)$ & $13(12.7)$ & $3(5.7)$ & $4(11.1)$ & $>0.05$ \\
\hline Dapagliflozin & $43(28.1)$ & $45(30.2)$ & $43(42.2)$ & $29(54.7)$ & $17(47.2)$ & 0.027 \\
\hline Dulaglutide & $19(12.4)$ & $21(14.1)$ & $12(11.8)$ & $13(24.5)$ & $12(33.3)$ & $>0.05$ \\
\hline Glargine (U-100) & $40(26.1)$ & $37(24.8)$ & $23(22.5)$ & $16(30.2)$ & $12(33.3)$ & 0.017 \\
\hline Glargine (U-300) & $27(17.6)$ & $24(16.1)$ & $12(11.8)$ & $7(13.2)$ & $8(22.2)$ & $>0.05$ \\
\hline $\mathrm{NPH}$ & $2(1.3)$ & $2(1.3)$ & $2(2)$ & $3(5.7)$ & $1(2.8)$ & $>0.05$ \\
\hline Lispro & $16(10.5)$ & $11(7.4)$ & $8(7.8)$ & $2(3.8)$ & $3(8.3)$ & $>0,05$ \\
\hline $\mathrm{NPH}$ /regular insulin & $16(10.5)$ & $17(11.4)$ & 19 (18.6) & $13(24.5)$ & $7(19.4)$ & $>0.05$ \\
\hline
\end{tabular}

Data are presented as frequencies (percentage). Q Cochran was performed for comparisons over time. *p-value for multiple comparisons.

Table 3. Main comorbidities

\begin{tabular}{lcccc}
\hline Comorbidities/time & $\begin{array}{c}\text { Baseline, } \\
\mathrm{n}=153\end{array}$ & $\begin{array}{c}12 \text { months, } \\
\mathrm{n}=99\end{array}$ & $\begin{array}{c}\text { 24 months, } \\
\mathrm{n}=35\end{array}$ & $\mathrm{p}$-value* \\
\hline Retinopathy & $14(9.2)$ & $10(9.8)$ & $5(13.9)$ & $>0.05$ \\
\hline Peripheral neurological symptoms*** & $20(13.1)$ & $27(26.5)$ & $16(44.4)$ & 0.009 \\
\hline Renal disease** & $13(8.5)$ & $12(7.8)$ & $10(6.5)$ & 0.05 \\
\hline Hearth failure & $6(3.9)$ & $6(5.8)$ & $5(13.9)$ & $>0.05$ \\
\hline Stroke & $3(2)$ & $3(2.9)$ & $2(5.6)$ & $>0.05$ \\
\hline Amputations & $0(0)$ & $0(0)$ & $0(0)$ & $>0.05$ \\
\hline Heart attack & $5(3.3)$ & $5(4.9)$ & $3(8.3)$ & $>0.05$ \\
\hline Angina & $3(2)$ & $4(3.9)$ & $2(5.6)$ & $>0.05$ \\
\hline
\end{tabular}

Data are presented as frequencies (percentage). Q Cochran was performed for comparisons over time. * $\mathrm{p}$-value for multiple comparisons. ${ }^{* *}$ Renal disease was considered positive with a glomerular filtration rate below $60 \mathrm{ml} / \mathrm{min}$; calculated with CDK-EPI formula. Only one patient progressed to Stage 5 and required dialysis during follow-up. ${ }^{* * *}$ Peripheral neurological symptoms were obtained by a medical chart concerning dysesthesia, paresthesia, pain, and numbness.

\section{DISCUSSION}

CoeD induced a sustained reduction in fasting glucose and $\mathrm{HbA1c}$ over a 2-year follow-up. Among all comorbidities, only peripheral neuropathy increased in prevalence. ER visits and hospitalizations remained stable threw time.

Previous meta-analyses results have reflected the effect of culturally appropriate programs to achieve glycemic control in the Latino/Hispanic population with diabetes, with follow-ups ranging between 6 and 24 months and reporting decreases in $\mathrm{HbA1C}$ between 0.25 and $0.53 \% \%^{6,8}$. The decreases in $\mathrm{HbA} 1 \mathrm{c}$ in CoeD patients were greater (1.5\%).

A study conducted in Mexico City that evaluated the impact of an institutional, educational program in patients with T2DM over a year showed decreases in fasting glucose of $33.7 \mathrm{mg} / \mathrm{dl}(p<0.001)$ and reductions in $\mathrm{HbA} 1 \mathrm{c}$ of $0.69 \%(p<0.001)^{12}$. Our population had worse baseline glucose control and was predominantly male. However, CoeD obtained 
comparable results, whereby our patients' fasting glucose decreased (8.05 mg/dl more), as well as their $\mathrm{HbA} 1 \mathrm{c}$ (0.81\% more).

Another study conducted in the south of Mexico assessed an educational intervention on glycemic control in 39 subjects. They reported a change in $\mathrm{HbA} 1 \mathrm{c}$ of $-1.11 \%$ (from $9.25 \%$ to $8.14 \% ; \mathrm{p}<0.001)^{13}$. In comparison, our patients had a sharp 6-month decrease in $\mathrm{HbA} 1 \mathrm{c}$ of $1.5 \%(0.4 \%$ more, $\mathrm{p}<0.001)$ sustained throughout follow-up.

Most of the previously reported studies have described a predominance of the female gender in their samples, and the most frequent follow-up period has been 6 months $s^{6-9,14,15}$. Our study's novelty is our sample: $75.2 \%$ were Mexican male active workers in the steel industry. This group is very difficult to reach due to their work schedules, and their poor adherence to treatment is commonplace. Most of the steelworkers have families and are their sole economic support. This program reinforced, empowered, and focused on the need for medical control to benefit the entire family and improve their quality of life. The reduction of $\mathrm{HbA} 1 \mathrm{c}$ was sustained throughout follow-up, and this may be a direct result of an increase in pharmacological and non-pharmacological adherence to medical and educational guidelines.

A study of 207 Mexican-Americans with $\mathrm{HbA} 1 \mathrm{c}>8 \%$ evaluated the effect of a culturally sensitive diabetes education program, in which patients had on target blood pressure readings since the beginning of the study ${ }^{9}$. CoeD showed similar results.

According to ENSANUT 2016, the prevalence of hospitalizations and ER visits in patients with T2DM is $16 \%$ and $14 \%$, respectively ${ }^{16}$. Our group had a higher baseline number of ER visits than reported nationwide $(26.1 \%)$, and it did not change over time $(30.6, p>0.05)$. The higher rate could result from a high risk of acute complications in this specific group or a high risk dependent on the steel industry per se. Steelworkers' workdays are related to difficulty in mealtimes, drug attachment, and also, they have more work accidents such as fractures or injuries. However, our hospitalization rate was lower than that reported nationwide, 3.3\%, and did not change over time. Furthermore, the lower rate of hospitalization is directly related to a lower rate of work absenteeism.

The chronic complications in diabetes are rarely followed by multidisciplinary interventions and not frequently reported in the literature in minorities. We only found three previous studies on the African-American population ${ }^{6}$. However, differences have been reported in terms of diabetes complication rates among different populations. In the Hispanic population, end-stage renal disease and retinopathy are highly prevalent ${ }^{17}$. ENSANUT 2016 reported patients with T2DM retinopathy in $11.2 \%$ of cases and kidney disease leading to dialysis in $1.2 \%$. Only one patient progressed to dialysis during follow-up in our population, and we observed no progression of retinopathy (13.9\%). The second most frequent chronic complication was peripheral neuropathy. This complication progressed in our patients throughout follow-up, with rates similar to previously reported (44.4\% at the end of follow-up) ${ }^{16}$.

In our study, two patients died due to cardiovascular disease during follow-up. It is well-known that patients with T2DM in Mexico have a risk of cardiovascular death $^{18}$. The previous studies have shown the relationship between glucose variability and oxidative stress as a physiopathological component for developing cardiovascular complications in T2DM ${ }^{19}$.

Although our patients had a significant and sustained decrease in $\mathrm{HbA} 1 \mathrm{c}$, some did not reach a value below $7 \%$. New strategies must be implemented to help these patients, such as a second-phase medical group visit and strong communication with the workers' leaders to help patients comply with the program. Educational programs for medical providers have also proved to be helpful ${ }^{20}$. It is well known that losing weight is beneficial for glucose control and reducing cardiovascular risk ${ }^{21}$, so our team must also implement complementary strategies to help patients lose weight.

Other limitations to our study were the non-randomization and the lack of a control group. After these favorable results, formal clinical trials with changes in prescription doses must be addressed in the future. Finally, a longer patient follow-up must be conducted to evaluate the progression of other chronic complications. 


\section{CONCLUSIONS}

CoeD successfully decreased and sustained lower $\mathrm{HbA} 1 \mathrm{c}$ and fasting glucose values over 2 years in a group of male steelworkers with $A 1 c \geq 9 \%$. We believe that this kind of intervention could be useful in populations where family support is pivotal to health care.

\section{ACKNOWLEDGMENT}

We are grateful to Iram Hernández for his support in the process of data collection.

\section{FUNDING}

This research did not receive a specific grant from funding agencies in the public, commercial, or non-profit sectors.

\section{CONFLICTS OF INTEREST}

The authors declare that there is no conflicts of interest.

\section{ETHICAL DISCLOSURES}

Protection of human and animal subjects. The authors declare that no experiments were performed on humans or animals for this study.

Confidentiality of data. The authors declare that they have followed the protocols of their work center on the publication of patient data.

Right to privacy and informed consent. The authors have obtained the written informed consent of the patients or subjects mentioned in the article. The corresponding author is in possession of this document.

\section{REFERENCES}

1. International Diabetes Federation. Worldwide Toll of Diabetes. Available from: https://www.diabetesatlas.org/en/sections/worldwide-toll-ofdiabetes.html [Last accessed on 2019 Nov 20].

2. Shamah-Levy T, Vielma-Orozco E, Heredia-Hernández O, Romero-Martínez M, Mojica-Cuevas J, Cuevas-Nasu L, et al. Encuesta Nacional de Salud y Nutrición 2018-19: Resultados Nacionales. Instituto Nacional de Salud Pública; 2018. Available from: https://www.ensanut.insp.mx/encuestas/ ensanut2018/doctos/informes/ensanut_2018_informe_final.pdf [Last accessed on 2021 Mar 15].

3. Skerjanc A. Sickness absence in diabetic employees. Occup Environ Med. 2001;58:432-36.

4. Diabetes Control and Complications Trial Research Group, Nathan DM Genuth S, Lachin J, Cleary P, Crofford O, et al. The effect of intensive treatment of diabetes on the development and progression of longterm complications in insulin-dependent diabetes mellitus. N Engl J Med. 1993;329:977-86.

5. King P, Peacock I, Donnelly R. The UK prospective diabetes study (UKPDS): clinical and therapeutic implications for Type 2 diabetes. $\mathrm{Br}$ Clin Pharmacol. 1999;48:643-8.

6. Creamer J, Attridge M, Ramsden M, Cannings-John R, Hawthorne K. Culturally appropriate health education for Type 2 diabetes in ethnic minority groups: an updated Cochrane review of randomized controlled trials. Diabet Med. 2016;33:169-83.

7. Brown SA, Blozis SA, Kouzekanani K, Garcia AA, Winchell M, Hanis CL. Dosage effects of diabetes self-management education for Mexican Americans: The Starr County border health initiative. Diabetes Care. 2005;28:527-32.

8. Ferguson S, Swan M, Smaldone A. Does diabetes self-management education in conjunction with primary care improve glycemic control in Hispanic patients?: a systematic review and meta-analysis. Diabetes Educ. 2015 41:472-84.

9. Philis-Tsimikas A, Fortmann A, Lleva-Ocana L, Walker C, Gallo LC. Peer-led diabetes education programs in high-risk Mexican Americans improve glycemic control compared with standard approaches: a project dulce promotora randomized trial. Diabetes Care. 2011;34:1926-31.

10. Vincent D, Clark L, Zimmer LM, Sanchez J. Using focus groups to develop a culturally competent diabetes self-management program for Mexican Americans. Diabetes Educ. 2006;32:89-97.

11. Cuschieri S. The STROBE guidelines. Saudi J Anaesth. 2019;13 Suppl 1:S31-4

12. Mendoza-Romo MA, Velasco-Chávez JF, de Jesús RN, Andrade-Rodríguez HJ, Rodríguez-Pérez CV, Palou-Fraga E. Impact of an educational institutional program in the control of the diabetic patient. Rev Med Inst Mex Seguro Soc. 2013:51:254-9.

13. Canché-Aguilar DL, Zapata-Vázquez RE, Rubio-Zapata HA, Cámara-Vallejos RM. Efecto de una intervención educativa sobre el estilo de vida, el control glucémico y el conocimiento de la enfermedad, en personas con diabetes mellitus Tipo 2, Bokobá, Yucatán. Rev Bioméd. 2019:30:3-11.

14. Culica D, Walton JW, Prezio EA. Code: community diabetes education for uninsured Mexican Americans. Bayl Univ Med Cent Proc. 2007;20:111-7.

15. Grillo MF, Neumann CR, Scain SF, Rozeno RF, Beloli L, Perinetto T, et al. Diabetes education in primary care: a randomized clinical trial. Cad Saúde Pública. 2016;32:e00097115.

16. Romero-Martínez M, Shamah-Levy T, Cuevas-Nasu L, Gómez-Humarán IM, Gaona-Pineda EB, Gómez-Acosta LM, et al. Diseño metodológico de la encuesta nacional de salud y nutrición de medio camino 2016. Salud Pública Méx. 2017;59:299.

17. Lanting LC, Joung IM, Mackenbach JP, Lamberts SW, Bootsma AH. Ethnic differences in mortality, end-stage complications, and quality of care among diabetic patients: a review. Diabetes Care. 2005;28:92280-8.

18. Alegre-Díaz J, Herrington W, López-Cervantes M, Gnatiuc L, Ramirez R Hill $M$, et al. Diabetes and cause-specific mortality in Mexico city. N Engl J Med. 2016;375:1961-71.

19. Martín-Timón I, Sevillano-Collantes C, Segura-Galindo A, del CañizoGómez FJ. Type 2 diabetes and cardiovascular disease: have all risk factors the same strength? World J Diabetes. 2014;5:444-70.

20. González-Guajardo EE, Salinas-Martínez AM, Botello-García A, MathiewQuiros. Clinical coaching in primary care: capable of improving contro in patients with Type 2 diabetes mellitus? Prim Care Diabetes. 2016;10:171-8

21. American Diabetes Association. 8. Obesity management for the treatment of type 2 diabetes: standards of medical care in diabetes-2020. Diabetes Care. 2020;43 Suppl 1:S89-97. 